\title{
Relationship between personality traits and reproductive choices among women attending the psychiatric clinic of a Nigerian Teaching Hospital
}

\author{
Boladale M. Mapayi ${ }^{1,2 *}$, Champion Seun-Fadipe ${ }^{2}$, Adesanmi Akinsulore ${ }^{1,2}$, Olutayo O. Aloba ${ }^{1,2}$, \\ Olukunle O. Oginni ${ }^{1,2}$, Theresa O. Ugalahi ${ }^{2}$
}

\author{
${ }^{1}$ Department of Mental Health, Obafemi Awolowo University, Ile-Ife, Nigeria \\ ${ }^{2}$ Department of Mental Health, Obafemi Awolowo University Teaching Hospitals Complex, Ile-Ife, Nigeria
}

Received: 27 December 2018

Accepted: 30 January 2019

\author{
*Correspondence: \\ Dr. Boladale M. Mapayi, \\ E-mail: daledosu@yahoo.com
}

Copyright: (c) the author(s), publisher and licensee Medip Academy. This is an open-access article distributed under the terms of the Creative Commons Attribution Non-Commercial License, which permits unrestricted non-commercial use, distribution, and reproduction in any medium, provided the original work is properly cited.

\begin{abstract}
Background: The study aimed to assess the relationship between personality traits and reproductive choices among women attending the psychiatric clinic at a Nigerian Teaching Hospital.

Methods: The original study used a quasi-experimental pre-test post-test-controlled design though this article presents a cross sectional view of results. Two hundred females were recruited into the study. An intervieweradministered questionnaire was applied to the respondents which elicited information on background characteristics, baseline contraceptive indicators and personality traits. Data were analyzed using both descriptive and inferential methods.

Results: The personality factors found to affect contraceptive use included high scores on Conscientiousness, Extraversion and Neuroticism, though only extraversion maintained this relationship on regression analysis. The personality factors found to affect pregnancy plan included high scores on Conscientiousness.

Conclusions: This study showed a distinct relationship between specific personality traits and contraceptive use with neuroticism exhibiting a negative influence on use while conscientiousness exhibited a positive influence.
\end{abstract}

Keywords: Contraception, women, Mental health, Personality factors

\section{INTRODUCTION}

There are wide variations in the factors that influence the decision of women to adopt or not to adopt the available family planning methods. Some women have erroneous beliefs about their risk of becoming pregnant while others have apprehensions about the health consequences and side effects of available contraceptive methods. In developing countries especially, resistance from the spouse and/or family members may discourage the woman from using contraceptives. ${ }^{1,2}$ In many developing countries, lack of access to the wide array of modern contraceptive methods limits women's choices. When many methods are made available, women usually report higher quality services and higher use of contraceptive. ${ }^{3}$ In a study in Nigeria, husbands approval was scored high as a determining factor in the utilization of contraceptives. ${ }^{4}$ Studies have shown that though many sexually active women with severe mental illnesses do not want to become pregnant, they do not use birth control. $^{5}$ In quite a number of studies, personality has shown associations with fertility preferences though some studies still disagree on direction of association. Personality refers to the characteristic pattern of thinking, feeling and acting. It is the consistent and distinctive ways that ideas, feelings and actions are organised. Personality is an important predictor of behavioural and health outcomes. ${ }^{6}$ The major theories in the study of 
personality include dispositional (trait) perspective, psychodynamic, humanistic, biological, behaviourist and social learning perspective. The five-factor model developed from the trait theories. It organises all personality traits along a continuum of five factors: openness, extraversion, conscientiousness, agreeableness, and neuroticism. ${ }^{7,8}$ The five factor personality traits show consistency in interviews, self-descriptions, and observations, as well as across a wide range of participants of different ages and from different cultures. There is evidence from research that there is a genetic basis for the five personality factors. ${ }^{9,10}$

Openness to experience can be described as a person's tendency to seek new experiences due to being creative, imaginative, unconventional, and emotionally sensitive. ${ }^{6}$ Open individuals are curious about both inner and outer worlds and their lives are experientially richer. ${ }^{11}$

Conscientiousness refers to an innate ability to control behavioural and cognitive impulses "that facilitates taskand goal-directed behaviour, such as thinking before acting, delaying gratification, following norms and rules, and planning, organizing, and prioritizing tasks". ${ }^{12}$ On the negative side, high Conscientiousness may lead to annoying fastidiousness, compulsive neatness or workaholic behaviour. Low Conscientiousness scores may not necessarily lack moral principles, but they are less exacting in applying them. ${ }^{11}$

Extraversion reflects a person's tendency to be outgoing, expressive, active, energetic, assertive, cheerful, sociable, and in search of stimulation. ${ }^{6}$ Extraversion is characterised by positive feelings and experiences and is therefore seen as a positive effect. ${ }^{13}$

Agreeableness can be defined as a person's pro-social and communal orientation and includes a person's tendency to be altruistic, trustworthy, cooperative, considerate, empathic, polite, and modest. ${ }^{6,12}$ Neuroticism indicates the general tendency to experience negative emotions such as anxiety, nervousness, sadness, and depression. ${ }^{6,12}$

Extraversion has been associated with higher probability of parenthood and having subsequent children among both males and females in Senegalese, Dutch, Finnish, and American samples. ${ }^{14-17}$ Neuroticism on the other hand has been associated with lower probability of parenthood and fewer number of children in Finnish, American, and German samples. ${ }^{14,15,18}$

Individuals with low agreeableness and low conscientiousness are more likely to engage in risky sexual behaviours including multiple sexual partners, lack of contraception and casual sex with strangers which might in turn increase the probability of unplanned pregnancies. ${ }^{19-21}$ High extraversion and sensation seeking tendencies have also been associated with sexual risk behaviour. $^{20}$ The results for neuroticism have been inconsistent. ${ }^{20}$ Conscientiousness is more strongly related to reproductive outcomes in women than in men. In the study by Berg et al, it was associated with lower probability of non-planned pregnancies and total number of children in women. ${ }^{22}$

Mental disorders represent a huge psychological, social and economic burden to society and also heighten the risk of physical illnesses. According to Gureje and colleagues, the prevalence of mental illness in Nigeria is about $20 \%$. $^{23,24}$

Mental illnesses do not affect both sexes equally, some mental disorders are more common in women and some others have slightly different symptoms in women while others still occur only among women. A lot of factors contribute to the development of mental illnesses in women and some of them are peculiar to them alone. Stress due to multiple roles in the home and at work and the increased likelihood of women to be poor, vulnerable to violence and abuse all play roles in the development of mental illnesses. ${ }^{25,26}$

Women who are mentally ill and women who abuse psychoactive substances might not be able to give consent to sexual activity and are less likely to use contraception according to standards that would make them effective and also have a higher possibility of sexual exploitation. ${ }^{27}$ Thus, it is imperative to pay attention to factors associated with the contraceptive behaviour of women living with mental illness including personality factors.

\section{METHODS}

\section{Participants and procedure}

The original study used a quasi-experimental pre-test post-test-controlled design, but this article reports on the personality factors associated with contraceptive decisions (contraceptive use and pregnancy planning) for females attending the psychiatric outpatient clinics at a Nigerian Tertiary hospital. The study population consisted of female patients in the reproductive age group (15-49yrs), attending the psychiatric outpatient clinic of the Obafemi Awolowo University Teaching Hospital Complex.

The minimum sample size was determined using the formula for calculating sample size for the comparison of two independent proportions. Proportion of all women currently using any contraceptive method in Nigeria was used at $16 \%(28)$.

To accommodate for a projected $10 \%$ attrition between respondents seen at base line and post-intervention, the calculated sample size of 89 per group was increased by $10 \%$ to 98 respondents per group. This gave an overall sample size of 98 respondents which was rounded up to 100 respondents per group, making 200 respondents for the study. 
Ethical approval was obtained from the Obafemi Awolowo University Teaching Hospitals Complex Ethical Review Committee. Informed consent was obtained from the participants after showing full understanding of the study.

Participants were also assured that their non-participation in or withdrawal from the study would not affect the quality of the treatment they receive. Confidentiality of information obtained from the respondents was ensured as access to respondents' information was restricted to researchers.

\section{Materials}

The instruments for this study included a modified version of the Nigeria Demographic and Health Survey instrument and the big five personality inventory (BFI). Broadly, the study instrument consisted of 4 sections:

- Section A consisted of questions to elicit information regarding age, present house address, occupation and other socio-demographic characteristics.

- Section B captured the reproductive health information.

- Section C evaluated their health seeking behaviour.

- Section D is the Big Five Personality Inventory (BFI)

The research inventory was transliterated into Yoruba language which is the main language in the area where the hospital is domiciled and its catchment areas. The transliteration was done by qualified linguists.

The transliterated document was then translated back into English by two other linguists who were not part of the original translation. Both versions of the transliterated instrument were compared for discrepancies. Copies of the questionnaire were administered (to intervention and control groups) by trained research assistants who received a two-day training on counselling methods and interviewing techniques by counsellors from the FP clinic and the principal investigator.

\section{Big Five Personality Inventory (BFI)}

This personality trait assessment scale was developed by John and Srivastava based on the five-factor model of personality assessment. ${ }^{29}$ It is a multi-item inventory of 44 traits commonly used to describe an individual in everyday language. The scale is divided into five dimensions typically referred to as Extraversion, Agreeableness, Conscientiousness, Neuroticism and Openness to Experience or Intellect.

The 44-item version of the Big Five Inventory (BFI) is scored on a four-point scale ranging from Strongly Disagree (which is denoted by a score of one) to Strongly Agree (denoted by a score of five). John and colleagues reported an overall Cronbach alpha of 0.80 and a threemonth test retest reliability of $0.85 .^{30}$
The BFI has been validated in Nigeria by Umeh (31) with a mean convergent validity coefficient of 0.75 and 0.85 when correlated with Big Five Inventory (32) and Big Five Inventory respectively. ${ }^{31-33}$ In Nigeria, Onyishi, et al. reported a Cronbach's alpha of $0.83 .{ }^{33,34}$ In scoring the $\mathrm{BFI}$, all negatively-keyed items were reverse-scored:

- Extraversion: 6, 21, 31

- Agreeableness: 2, 12, 27, 37

- Conscientiousness: 8, 18, 23, 43

- Neuroticism: 9, 24, 34

- Openness: 35, 41

To recode the items, the scores for all reverse-scored items were subtracted from 6 . That is, a score of 1 becomes 5, 2 becomes 4, 3 remains 3, 4 becomes 2, and 5 becomes 1 . Then a scale score was created by averaging the following items for each domain (where $\mathrm{R}$ indicates using the reverse-scored item).

- Extraversion: 1, 6R 11, 16, 21R, 26, 31R, 36

- Agreeableness: 2R, 7, 12R, 17, 22, 27R, 32, 37R, 42

- Conscientiousness: 3, 8R, 13, 18R, 23R, 28, 33, 38, 43R

- $\quad$ Neuroticism: 4, 9R, 14, 19, 24R, 29, 34R, 39

- Openness: 5, 10, 15, 20, 25, 30, 35R, 40, 41R, 44

\section{Analysis}

Of the 200 respondents, the data from the 167 participants $(83.5 \%)$ who answered the item of the questionnaire requesting for information about unplanned pregnancy were included in the final analysis. Data was analysed using the Statistical Package for Social Sciences (SPSS, Chicago, IL) version 22. The data were summarized using descriptive statistics such as proportion, frequency, and mean. The Chi square and Student $\mathrm{t}$ tests were used to explore associations between variables. Binary logistic regression was used to determine the predictors with unplanned pregnancy and the use of contraceptives being the dependent variable. A $\mathrm{p}$ value of 0.05 was considered statistically significant in all cases.

\section{RESULTS}

\section{Sociodemographic and mental health characteristics of the participants}

The respondents' ages ranged between 20 and 49 years with a mean of 38.0 (7.1) years and majority (71.9\%) were married in a monogamous family setting $(61.7 \%)$. They were mostly $(95.8 \%)$ of Yoruba tribe and about three-fifth $(58.1 \%)$ were artisan/trader. Only 64 of the respondents $(38.3 \%)$ successfully completed their tertiary education. Regarding their mental health characteristics, most of the respondents $(70.7 \%)$ were diagnosed with schizophrenia. About one-third (34.8\%) indicated they had suicidal thoughts and 16 respondents (9.6\%) expressed previous suicidal attempts (Table 1). 
Reproductive characteristics, contraceptive use and personality traits of the respondents

Regarding their reproductive characteristics, about $70 \%$ of the respondents indicated they had their first sex, first marriage and first birth between 20-29 years. The mean ages (SD) of first sex, first marriage and first birth were 22.5 (4.4), 25.1 (4.8) and 25.9 (5.4) respectively. More than half of the respondents $(56.6 \%)$ had between 2 and 4 pregnancies, with the mean number of pregnancies being $3.2(1.8)$.

Table 1: Sociodemographic characteristics and mental health characteristics in association with unplanned pregnancy.

\begin{tabular}{|c|c|c|c|c|c|c|}
\hline \multirow{2}{*}{ Variables } & \multirow{2}{*}{ Total $(\%) \mathrm{n}=167$} & \multicolumn{2}{|c|}{ Unplanned pregnancy } & \multicolumn{3}{|c|}{ Statistics } \\
\hline & & Yes $(\%), n=56$ & No $(\%), n=111$ & $\chi^{2}$ & df & p value \\
\hline Age group (years) & & & & 2.45 & 2 & 0.30 \\
\hline $20-29$ & $21(12.6)$ & $10(17.9)$ & $11(9.9)$ & & & \\
\hline $30-39$ & $68(40.7)$ & $23(41.1)$ & $45(40.5)$ & & & \\
\hline$\geq 40$ & $78(46.7)$ & $23(41.1)$ & $55(49.5)$ & & & \\
\hline Marital status & & & & 10.60 & 2 & $<0.01$ \\
\hline Single & $14(8.4)$ & $10(17.9)$ & $4(3.6)$ & & & \\
\hline Married & $120(71.9)$ & $34(60.7)$ & $86(77.5)$ & & & \\
\hline Separated/ divorced/widowed & $33(19.8)$ & $12(21.4)$ & $21(18.9)$ & & & \\
\hline Religion & & & & 4.66 & & $0.07 *$ \\
\hline Christian & $129(77.2)$ & $47(83.9)$ & $82(73.9)$ & & & \\
\hline Islam & $37(22.2)$ & $8(14.3)$ & $29(26.1)$ & & & \\
\hline Traditional & $1(0.6)$ & $1(1.8)$ & $0(0.0)$ & & & \\
\hline Educational level & & & & 2.09 & 2 & 0.35 \\
\hline Primary & $44(26.3)$ & $13(23.2)$ & $31(27.9)$ & & & \\
\hline Secondary & $59(35.3)$ & $24(42.9)$ & $35(31.5)$ & & & \\
\hline Tertiary & $64(38.3)$ & $19(33.9)$ & $45(40.5)$ & & & \\
\hline Occupation & & & & 1.03 & 2 & 0.60 \\
\hline Civil servant & $29(17.4)$ & $8(14.3)$ & $21(18.9)$ & & & \\
\hline Artisan/Trader & $97(58.1)$ & $32(57.1)$ & $65(58.6)$ & & & \\
\hline Unemployed & $41(24.6)$ & $16(28.6)$ & $25(22.5)$ & & & \\
\hline Tribe & & & & & & $0.04 *$ \\
\hline Yoruba & $160(95.8)$ & $51(91.1)$ & $109(98.2)$ & & & \\
\hline Others & $7(4.2)$ & $5(8.9)$ & $2(1.8)$ & & & \\
\hline Family type & & & & 2.26 & 1 & 0.13 \\
\hline Monogamous & $103(61.7)$ & $39(69.6)$ & $64(57.7)$ & & & \\
\hline Polygamous & $64(38.3)$ & $17(30.4)$ & $47(42.3)$ & & & \\
\hline Diagnosis & & & & 0.13 & 2 & 0.94 \\
\hline Schizophrenia & $118(70.7)$ & $39(69.6)$ & $79(71.2)$ & & & \\
\hline Affective Disorders & $33(19.8)$ & $11(19.6)$ & $22(19.8)$ & & & \\
\hline Others & $16(9.6)$ & $6(10.7)$ & $10(9.0)$ & & & \\
\hline Suicidal thought & & & & 6.79 & 1 & 0.01 \\
\hline Yes & $57(34.8)$ & $27(48.2)$ & $30(27.8)$ & & & \\
\hline No & $107(65.2)$ & $29(51.8)$ & $78(72.2)$ & & & \\
\hline Suicidal attempt & & & & 2.10 & 1 & 0.15 \\
\hline Yes & $16(9.6)$ & $8(14.3)$ & $8(7.3)$ & & & \\
\hline No & $150(90.4)$ & $48(85.7)$ & $102(92.7)$ & & & \\
\hline
\end{tabular}

Twenty-nine individuals (18.6\%) reported the number of children they have were not planned for while $83(50.0 \%)$ will like to have more children. The prevalence of unplanned pregnancy was $33.5 \%$ (Table 2). One hundred and thirty-four $(80.2 \%)$ reported they currently had a sexual partner while $161(96.4 \%)$ indicated lifetime experience of having sexual partners. Although about two third $(72.5 \%)$ indicated lifetime use of contraceptives, only about one-third (35.9\%) reported current use of contraceptives. 
A large proportion of the respondents $(63.1 \%)$ considered the quality of their marital relationship to be good while about one fourth reported an experience of intimate partner violence. Twenty-three $(14.0 \%)$ reported having sex without consent. Among the five dimensions of personality measured, agreeableness had the highest mean score (4.13) followed by conscientiousness (4.01), openness (3.20), neuroticism (2.90) and extraversion (2.88) (Table 3).

Table 2: Reproductive characteristics and contraceptive use in association with unplanned pregnancy.

\begin{tabular}{|c|c|c|c|c|c|c|}
\hline \multirow{2}{*}{ Variables } & \multirow{2}{*}{ Total (\%), n= 167} & \multicolumn{2}{|c|}{ Unplanned pregnancy } & \multicolumn{3}{|c|}{ Statistics } \\
\hline & & Yes $(\%), n=56$ & No $(\%), n=111$ & $\chi^{2}$ & df & p value \\
\hline Age at first sex (years) & & & & 7.63 & 2 & 0.02 \\
\hline$<20$ & $36(21.6)$ & $19(33.9)$ & $17(15.3)$ & & & \\
\hline $20-29$ & $117(70.1)$ & $33(58.9)$ & $84(75.7)$ & & & \\
\hline$\geq 30$ & $14(8.4)$ & $4(7.1)$ & $10(9.0)$ & & & \\
\hline Age at first marriage (years)* & & & & 3.20 & 2 & 0.20 \\
\hline$<20$ & $15(9.7)$ & $7(15.2)$ & $8(7.3)$ & & & \\
\hline $20-29$ & $111(71.6)$ & $33(71.7)$ & $78(71.6)$ & & & \\
\hline$\geq 30$ & $29(18.7)$ & $6(13.0)$ & $23(21.1)$ & & & \\
\hline Age at first birth (years) & & & & 10.29 & 2 & 0.01 \\
\hline$<20$ & $11(7.0)$ & $7(14.3)$ & $4(3.7)$ & & & \\
\hline $20-29$ & $111(70.7)$ & $37(75.5)$ & $74(68.5)$ & & & \\
\hline$\geq 30$ & $35(22.3)$ & $5(10.2)$ & $30(27.8)$ & & & \\
\hline Number of pregnancies & & & & 6.97 & 2 & 0.03 \\
\hline$<2$ & $33(19.9)$ & $16(28.6)$ & $17(15.5)$ & & & \\
\hline $2-4$ & $94(56.6)$ & $24(42.9)$ & $70(63.6)$ & & & \\
\hline$>4$ & $39(23.5)$ & $16(28.6)$ & $23(20.9)$ & & & \\
\hline Children Unplanned for & & & & 43.60 & 1 & $<0.01$ \\
\hline Yes & $29(18.6)$ & $24(49.0)$ & $5(4.7)$ & & & \\
\hline No & $127(81.4)$ & $25(51.0)$ & $102(95.3)$ & & & \\
\hline Want more children & & & & 3.88 & 1 & 0.05 \\
\hline Yes & $83(50.0)$ & $34(60.7)$ & $49(44.5)$ & & & \\
\hline No & $83(50.0)$ & $22(39.3)$ & $61(55.5)$ & & & \\
\hline Sexual partners (current) & & & & 3.38 & 1 & 0.07 \\
\hline 1 & $124(92.5)$ & $39(86.7)$ & $85(95.5)$ & & & \\
\hline$\geq 2$ & $10(7.5)$ & $6(13.3)$ & $4(4.5)$ & & & \\
\hline Sexual partners (Ever) & & & & 6.63 & 1 & 0.01 \\
\hline 1 & $87(54.0)$ & $22(40.0)$ & $65(61.3)$ & & & \\
\hline$\geq 2$ & $74(46.0)$ & $33(60.0)$ & $41(38.7)$ & & & \\
\hline Lifetime Contraceptive use & & & & 0.89 & 1 & 0.35 \\
\hline Yes & $121(72.5)$ & $38(67.9)$ & $83(74.8)$ & & & \\
\hline No & $46(27.5)$ & $18(32.1)$ & $28(25.2)$ & & & \\
\hline Contraceptive use (Current) & & & & 0.00 & 1 & 0.97 \\
\hline Yes & $60(35.9)$ & $20(35.7)$ & $40(36.0)$ & & & \\
\hline No & $107(64.1)$ & $36(64.3)$ & $71(64.0)$ & & & \\
\hline Quality of relationship & & & & 1.26 & 1 & 0.26 \\
\hline Poor & $59(36.9)$ & $22(43.1)$ & 37 (33.9) & & & \\
\hline Good & $101(63.1)$ & $29(56.9)$ & $72(66.1)$ & & & \\
\hline Intimate partner violence & & & & 9.20 & 1 & $<0.01$ \\
\hline Yes & $44(26.5)$ & $23(41.1)$ & $21(19.1)$ & & & \\
\hline No & $122(73.5)$ & $33(58.9)$ & 89 (80.9) & & & \\
\hline Sex without consent & & & & 3.87 & 1 & 0.05 \\
\hline Yes & $23(14.0)$ & $12(21.4)$ & $11(10.2)$ & & & \\
\hline No & $141(86.0)$ & $44(78.6)$ & $97(89.8)$ & & & \\
\hline
\end{tabular}

* $\mathrm{n}=155$ (12 missing variables), \# $\mathrm{n}=157$ (10 missing variables) 


\section{Factors associated with unplanned pregnancy}

The study observed that significantly more single and separated/divorced/widowed respondents than married respondents had unplanned pregnancies ( $\mathrm{p}<0.01)$. while respondents belonging to other tribes other than Yoruba had significantly more unplanned pregnancies $(\mathrm{p}=0.04)$.
Other sociodemographic factors did not have any significant association with unplanned pregnancy (Table 1). The proportion of respondents with unplanned pregnancies who expressed suicidal thoughts were more than those with planned pregnancies. This observation was statistically significant $(\mathrm{p}=0.01)$. Other mental health characteristics did not have any significant association with unplanned pregnancy (Table 1).

Table 3: Association between personality traits and unplanned pregnancy.

\begin{tabular}{|l|l|l|l|l|l|l|}
\hline \multirow{2}{*}{ Variable } & Mean & Unplanned pregnancy & \multicolumn{2}{l|}{ Statistics } \\
\hline Extraversion & $2.88(0.69)$ & $2.89(0.67)$ & $2.87(0.70)$ & 0.14 & 165 & 0.89 \\
\hline Openness & $3.20(0.53)$ & $3.18(0.44)$ & $3.22(0.57)$ & -0.48 & 165 & 0.64 \\
\hline Conscientiousness & $4.01(0.60)$ & $3.86(0.65)$ & $4.09(0.57)$ & -2.41 & 165 & 0.02 \\
\hline Agreeableness & $4.13(0.55)$ & $4.04(0.54)$ & $4.18(0.56)$ & -1.55 & 165 & 0.12 \\
\hline Neuroticism & $2.90(0.72)$ & $2.92(0.63)$ & $2.89(0.76)$ & 0.274 & 165 & 0.78 \\
\hline
\end{tabular}

Table 4: Predictors of Unplanned pregnancy.

\begin{tabular}{|c|c|c|c|}
\hline Variable & AOR & $95 \% \mathrm{CI}$ & $\begin{array}{l}P \\
\text { value }\end{array}$ \\
\hline \multicolumn{4}{|l|}{ Marital status } \\
\hline Single & Reference & & \\
\hline Married & 0.25 & $0.03-2.31$ & 0.22 \\
\hline Separated/ divorced & 0.33 & $0.03-3.65$ & 0.37 \\
\hline Widowed & 0.21 & $0.01-5.83$ & 0.36 \\
\hline \multicolumn{4}{|l|}{ Tribe } \\
\hline Others & Reference & & \\
\hline Yoruba & 0.00 & 0.00 & 0.99 \\
\hline \multicolumn{4}{|c|}{ Number of pregnancies } \\
\hline$<2$ & Reference & & \\
\hline $2-4$ & 0.78 & $0.15-4.19$ & 0.77 \\
\hline$>4$ & 0.78 & $0.12-4.91$ & 0.79 \\
\hline \multicolumn{4}{|c|}{ Children unplanned for } \\
\hline No & Reference & & \\
\hline Yes & 30.33 & $0.80-115.1$ & $<0.01$ \\
\hline \multicolumn{4}{|c|}{ Sexual partners (ever) } \\
\hline 1 & Reference & & \\
\hline$\geq 2$ & 3.36 & $1.07-10.50$ & 0.04 \\
\hline \multicolumn{4}{|c|}{ Intimate partner violence } \\
\hline No & Reference & & \\
\hline Yes & 2.24 & $0.76-6.61$ & 0.14 \\
\hline \multicolumn{4}{|c|}{ Age at first sex (years) } \\
\hline$<20$ & Reference & & \\
\hline $20-29$ & 0.41 & $0.11-1.56$ & 0.19 \\
\hline$\geq 30$ & 0.35 & $0.17-7.13$ & 0.49 \\
\hline \multicolumn{4}{|c|}{ Age at first birth (years) } \\
\hline$<20$ & Reference & & \\
\hline $20-29$ & 0.83 & $0.09-7.83$ & 0.87 \\
\hline$\geq 30$ & 0.25 & $0.02-3.70$ & 0.31 \\
\hline Conscientiousness & 0.92 & $0.84-1.02$ & 0.11 \\
\hline
\end{tabular}

The age at first sex $(p=0.02)$, age at first birth $(p=0.01)$, lifetime history of sexual partners $(\mathrm{p}=0.01)$, number of pregnancy $(\mathrm{p}=0.03)$, children unplanned for $(\mathrm{p}<0.01)$ and intimate partner violence $(\mathrm{p}<0.01)$ had statistically significant associations with unplanned pregnancy (Table 2). Compared to other age group categories, respondents who were younger than 20 years when they had their first sex had more unplanned pregnancies.

While those younger than 30 years when they had the first child delivery reported more unplanned pregnancies than those aged 30 years or higher.

Respondents who reported they had been pregnant between 2-4 times had better pregnancy plans than those with only one previous pregnancy and those who had been pregnant more than 4 times. Furthermore, more respondents who planned the number of their children made pregnancy plans than those who didn't make any plans while those that have had more than one sexual partner in their lifetime reported more unplanned pregnancies than those with only one sex partner. Also, respondents who had experienced intimate partner violence had more unplanned pregnancies when compared to those who had not. Of the personality traits, only conscientiousness had a significant ( $p=0.02)$ association with unplanned pregnancy. Respondents with unplanned pregnancy reported lower mean scores on conscientiousness when compared to those who planned their pregnancies (Table 3).

\section{Predictors of unplanned pregnancy}

Authors performed binary logistic regression with unplanned pregnancy as the dependent variable (Table 4). This was to identify independent predictors of unplanned pregnancy; thus, all the variables who had statistically 
significant associations with unplanned pregnancy were included in the model as independent variables.

The Omnibus Test of Model Coefficient (df) was $\chi 2=75.94$ (14) $p<0.01$ while the model accounted for $40.3 \%$ to $56.5 \%$ of the variability in unplanned pregnancy (Cox and Snell $R$ square $=0.403$ and Nagelkerke R square=0.565). Of all the factors evaluated, not planning for children and lifetime sex partners retained their associations with unplanned pregnancy (Table 4).

Respondents who did not plan for their children were 30.3 times more likely to have unplanned pregnancy when compared to those who had a plan for their children (95\% CI=0.80-115.16, $\mathrm{p}<0.01)$.

Similarly, those who had more than one sexual partner in their lifetime were 3.4 times more likely to have unplanned pregnancy than those with only one partner (95\% CI=1.07 -10.50, p=0.04).

\section{Personality traits associated with contraceptive use}

Table 5 shows the comparison of mean scores on personality between those using contraceptives and those not using. Mean extraversion score for those using contraceptive was significantly higher than those who reported they were not using contraceptives $(\mathrm{p}<0.01$ ) while individuals using contraceptives were significantly more conscientious than those not using $(\mathrm{p}=0.01)$. Respondents who were not using contraceptives had significantly higher score on neuroticism than those who were using ( $\mathrm{p}<0.01)$. Other traits did not have any significant association with use of contraceptives.

\section{Personality predictors of contraceptive use}

This relationship was somewhat modified on multivariate analysis using binary logistic regression as only the personality dimension of extraversion showed an association with contraceptive use. Respondents with high extraversion scores were 2 times more likely to use contraceptives $(\mathrm{p}=0.007)$ (Table 5).

Table 5: Association between personality traits and contraceptive use.

\begin{tabular}{|l|l|l|l|l|l|l|l|}
\hline \multirow{2}{*}{ Variable } & Yes & Nontraceptive use & \multicolumn{2}{c|}{ Statistics } & \multicolumn{2}{l|}{ Multiple Logistic Regression } \\
\hline & Mean (SD) & Mean (SD) & & df & p value & AOR & 95\% CI \\
\hline Extraversion & $3.10(0.60)$ & $2.75(0.70)$ & 3.28 & 165 & $<0.01$ & 2.01 & $1.20-3.37$ \\
\hline Openness & $3.30(0.54)$ & $3.15(0.52)$ & 1.74 & 165 & 0.08 & & \\
\hline Conscientiousness & $4.17(0.57)$ & $3.92(0.61)$ & 2.54 & 165 & 0.01 & 1.47 & $0.78-2.75$ \\
\hline Agreeableness & $4.18(0.57)$ & $4.10(0.54)$ & 0.86 & 165 & 0.39 & & \\
\hline Neuroticism & $2.70(0.70)$ & $3.02(0.70)$ & -2.83 & 165 & $<0.01$ & 0.65 & $0.38-1.12$ \\
\hline
\end{tabular}

AOR: Adjusted Odds Ratio; 95\% CI: 95\% Confidence Interval

\section{DISCUSSION}

One hundred and sixty-seven women with various mental health challenges attending the Ife and Ilesa psychiatric units of Obafemi Awolowo University Teaching Hospital Complex participated in this survey.

\section{Personality factors and unplanned pregnancy}

This study found that the personality dimension of conscientiousness was associated with planning of pregnancy as women with higher scores on conscientiousness planned their pregnancies better. Berg and colleagues in their study found that conscientiousness was more strongly related to reproductive outcomes in women than in men.

It was associated with lower probability of pregnancies and total number of children in women, as has been shown in some other studies. ${ }^{15,22,35}$ They posited that the reduction in fertility rates in women was mainly caused by the lower number of nonplanned rather than planned pregnancies. In line with the findings of this study, Berg and colleagues argued that traits correlating with lower probability of non-planned pregnancies or births (emotional stability, conscientiousness and openness to experience in women) may correlate with the utilization of modern family planning methods. Sinha and Mishra, in their study of personality factors underlying attitude towards family planning found that high extroverts were more positive in their attitudes towards family planning.

However, neuroticism was unrelated to attitude towards family planning. These findings are similar with the findings in this study. ${ }^{22,36}$

\section{Personality factors and contraceptive use}

The mean scores on the five dimensions of personality measured are comparable with results obtained from another study in Nigeria, though respondents in this study had marginally higher scores on agreeableness (4.1 
compared with 3.3) and conscientiousness (4.0 compared with 3.2). ${ }^{37}$ The openness scores were same for both samples (3.5) while extraversion and neuroticism scores were lower (2.9 compared with 3.2 and 2.8 compared with 3.1 respectively). Those who used contraceptives had higher scores on extraversion and conscientiousness while those who did not use contraceptives had higher scores on neuroticism. This trend is expected when one looks at the Facet (and correlated trait adjective) for the different dimensions. People with high extraversion scores tend to be sociable, assertive, energetic, adventurous, full of warmth and positive emotions while people with high conscientiousness scores tend to be efficient, organized, dutiful, thorough and selfdisciplined.

On the other hand, people with high neuroticism scores tend to be anxious, irritable, depressed, self-conscious, impulsive and lack self-confidence. ${ }^{38}$ In concordance with the preceding discourse, Geissler in a study among 306 women and 304 men found that successful family planning was characterized by stable personality characteristics of minimal anxiety, steady concept of social responsibility, less depressive tendencies, more feminine women, less masculine men and higher intelligence in men. Berg and colleagues in their study among a British cohort found that extraversion was associated with having planned pregnancies only in men. 22,39

Limitations of the study include the fact that it was carried out in one state among a small population of women living with mental illness and cannot be generalized to all Nigerian women. The diagnosis also relied on the existing diagnosis, but this usually follows standard of ICD in everyday practice and is not expected to be any less reliable. Also, the study is cross sectional in nature and can only give a snap shot view of the variables studied.

\section{CONCLUSION}

This study showed a distinct relationship between specific personality traits and contraceptive use with neuroticism exhibiting a negative influence on use while conscientiousness exhibited a positive influence.

\section{ACKNOWLEDGMENTS}

Authors would like to acknowledge all the patients who participated in this study. Special appreciation to the entire staff of the department of Mental Health and the family planning unit OAUTHC for their valuable role in the actualization of this project.

Funding: This research was supported by the Consortium for Advanced Research Training in Africa (CARTA). CARTA is jointly led by the African Population and Health Research Center and the University of the Witwatersrand and funded by the Carnegie Corporation of New York (Grant No--B 8606.R02), Sida (Grant No:54100113), the DELTAS Africa Initiative (Grant No: 107768/Z/15/Z) and Deutscher Akademischer Austauschdienst (DAAD). The DELTAS Africa Initiative is an independent funding scheme of the African Academy of Sciences (AAS)'s Alliance for Accelerating Excellence in Science in Africa (AESA) and supported by the New Partnership for Africa's Development Planning and Coordinating Agency (NEPAD Agency) with funding from the Wellcome Trust (UK) and the UK government. The statements made and views expressed are solely the responsibility of the Fellow.

Conflict of interest: None declared

Ethical approval: Ethical approval was obtained from the Obafemi Awolowo University Teaching Hospitals Complex Ethical Review Committee

\section{REFERENCES}

1. Sedgh G, Hussain R, Bankole A, Singh S. Women with an unmet need for contraception in developing countries and their reasons for not using a method. Occasional Report. 2007;37:5-40.

2. Obisesan KA, Adeyemo AA, Fakokunde BO. Awareness and use of family planning methods among married women in Ibadan, Nigeria. East African Med J. 1998;75(3):135-8.

3. Ross J. Contraceptive method choice in developing countries. Int Fam Plan Perspect. 2001;28(1):32-40.

4. Moronkola OA, Ojediran MM, Amosu A. Reproductive health knowledge, beliefs and determinants of contraceptives use among women attending family planning clinics in Ibadan, Nigeria. African Health Sci. 2006;6(3):155-9.

5. Coverdale JH, Aruffo JA. Family planning needs of female chronic psychiatric outpatients. Am J Psychia. 1989;146(11):1489-91.

6. Terracciano A, Löckenhoff CE, Crum RM, Bienvenu OJ, Costa PT. Five-Factor Model personality profiles of drug users. BMC Psychia. 2008;8(1):22.

7. Watson JB. Psychology as the Behaviorist Views it. Psychological Review. 1913;20(2):158-77.

8. McCrae RR, Costa PT. Personality in adulthood. New York: Guilford Press; 1990.

9. Digman JM. Five robust trait dimensions: Development, stability, and utility. J Personal. 1989;57(2):195-214.

10. Jang KL, Livesley WJ, Vernon PA. Hereditability of the big five personality dimensions and their facets: A twin study. J Personal. 1996;64(3):577-91.

11. Rothmann S, Coetzer EP. The big five personality dimensions and job performance. SA J Indus Psychol. 2003;29(1):68-74.

12. Caspi A, Roberts BW, Shiner RL. Personality development: stability and change. Annu Rev psychol. 2005;56:453-84.

13. Clark LA, Watson D. General affective dispositions in physical and psychological health. Handbook Social Clinical Psychol. 1991:221-45. 
14. Jokela M, Keltikangas-Järvinen L. Adolescent leadership and adulthood fertility: Revisiting the Central theoretical problem of human sociobiology. J Personal. 2009;77(1):213-30.

15. Jokela M, Alvergne A, Pollet TV, Lummaa V. Reproductive behaviour and personality traits of the Five Factor Model. European J Personal. 2011;25(6):487-500.

16. Alvergne A, Jokela M, Lummaa V. Personality and reproductive success in a high-fertility human population. Proceed Nat Acad Sci USA. 2010;107(26):11745-50.

17. Dijkstra P, Barelds DPH. Women's well-being: The role of individual differences. Scandinavian J Psychol. 2009;50(4):309-15.

18. Reis O, Doernte M, von der Lippe H. Neuroticism, social support, and the timing of first parenthood: A prospective study. Personal Indi Dif. 2011;50(3):381-6.

19. Miller JD, Lynam D, Zimmerman RS, Logan TK, Leukefeld C, Clayton R. The utility of the Five Factor Model in understanding risky sexual behavior. Personal Indi Dif. 2004;36(7):1611-26.

20. Turchik JA, Garske JP, Probst DR, Irvin CR. Personality, sexuality and substance use as predictors of sexual risk taking in college students. J Sex Res. 2010;47(5):411-9.

21. Hoyle RH, Fejfar MC, Miller JD. Personality and sexual risk taking: A quantitative review. J Personal. 2000;68(6):1203-31.

22. Berg V, Rotkirch $\mathrm{A}$, Väisänen $\mathrm{H}$, Jokela $\mathrm{M}$. Personality is differentially associated with planned and non-planned pregnancies. $J$ Res Personal. 2013;47(4):296-305.

23. WHO. Disease and injury country estimates: Burden of Disease 2004b [Available from: www.who.int/healthinfo/global_burden_disease/esti mates_country/en/index.html.

24. Gureje O, Chisholm D, Kola L, Lasebikan V, Saxena S. Cost-effectiveness of an essential mental health intervention package in Nigeria. World psychiatry: $\mathrm{J}$ World Psychiatric Ass. 2007;6(1):42-8.

25. NIH. Women Hold Up Half the Sky, Women and Mental Health Research. 2001:01-4607

26. Sen G, Ostlin P, George A. Unequal unfair ineffective and inefficient. Gender inequity in health: Why it exists and how we can change it. 2007.

27. WHO Mental health aspects of women's reproductive health: a global review of the literature: World Health Organization; 2009.

28. National Population Commission [Nigeria] and ICF International. Nigeria Demographic and Health Survey 2013. Abuja, Nigeria, and Rockville, Maryland, USA: NPC and ICF International, 2014.
29. Adenuga AR, Ayodele OK. Adolescents' Entrepreneurial Behaviour: The predicitive effect of the Big Five personality factors. Europe J Business Social Sci. 2013;1(12):48-58.

30. John OP, Donahue EM, Kentle RL. The Big Five Inventory--Versions 4a and 54. Berkeley, CA: University of California, Berkeley, Institute of Personality and Social Research; 1991.

31. Umeh CS. The impact of personality characteristics on student's adjustment on campus. Unpublished Ph. D. Research monograph, Department of Psychology University of Lagos. 2004.

32. Costa PT, McCrae RR. Revised NEO Personality Inventory (NEO-PI-R and NEO five - factor (NEOFFI) Inventory Professional Manual. Odessa, FL: PAR; 1992.

33. Goldbery LR. The Development of markers for the Big Five Factor structure. Psychol Asses. 1992;4(1):26-42.

34. Onyishi I, Okongwu OE, Ugwu FO. Personality and social support as predictors of life satisfaction of Nigerian prison officers. European Scientific Journal. 2012;8(20):110-25.

35. Jokela M, Hintsa T, Hintsanen M, KeltikangasJärvinen L. Adult temperament and childbearing over the life course. Europe J Personal. 2010;24(2):151-66.

36. Sinha BN, Mishra NN. A study of Some Personality Factor understanding attitude towards family Planning. Indian J App Psychol. 1994;31(1):1-5.

37. Mosaku SK, Akinsulore A, Onwuchekwa IJ, Ibigbami OI, Fatoye FO. Personality Traits among Inmates of Aba Prison in Nigeria: Influence of the Five Factor Model on Inmate Status and type of Offences. Nigerian J Psychiat. 2013;12(2):9-15.

38. John OP, Srivastava S. The Big Five trait taxonomy: History, measurement, and theoretical perspectives. Handbook of personality: Theory Res. 1999;2(1999):102-38.

39. Geissler A. Psychological determinants of the desire for children and its fulfillment (an empirical report)] Psychological conditions of the wish to have a child and its fulfillment (empirical communication). Z Gesamte Hyg. 1981;27(7):522-5.

Cite this article as: Mapayi BM, Fadipe CS, Akinsulore A, Aloba OO, Oginni OO, Ugalahi TO. Relationship between personality traits and reproductive choices among women attending the psychiatric clinic of a Nigerian Teaching Hospital. Int J Reprod Contracept Obstet Gynecol 2019;8:892900. 